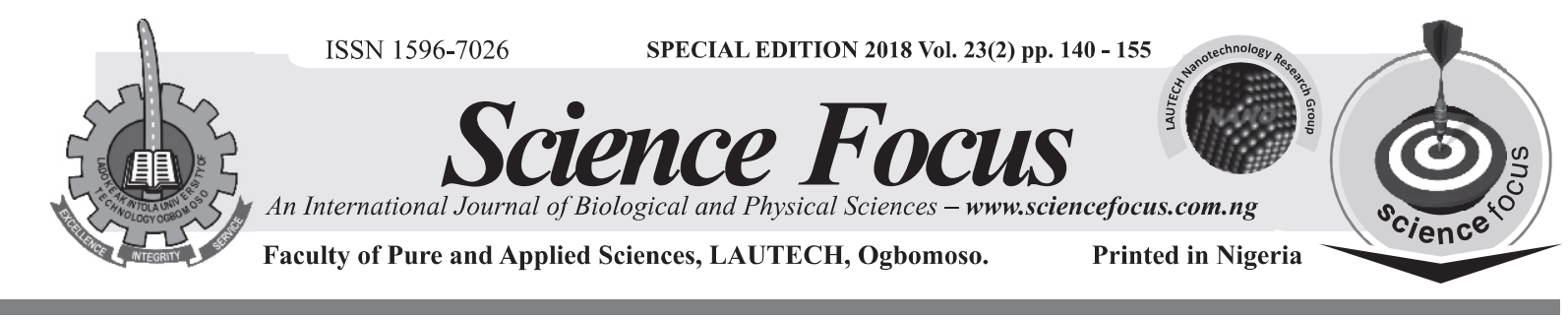

https://doi.org/10.36293/sfj.2019.0015

\title{
EFFECTS OF RICE HUSK ASH AND GRAPHENE ON MORPHOLOGICAL AND MECHANICAL PROPERTIES OF RECYCLED ALUMINIUM CANS HYBRID COMPOSITES.
}

\author{
Yekinni, A.A ${ }^{1,2^{*}}$, Durowoju, M.O ${ }^{2}$, Agunsoye, ${\mathrm{J} . O^{3}}^{3}$ and Mudashiru, L.O ${ }^{2}$ \\ ${ }^{1,2}$ Department of Mechanical Engineering, Lagos State Polytechnic, Ikorodu, Nigeria, \\ ${ }^{2}$ Department of Mechanical Engineering, Ladoke Akintola University of Technology, Ogbomoso, \\ Nigeria, ${ }^{3}$ Department of Metallurgical and Materials Engineering, University of Lagos, Akoka,
}

Nigeria

\begin{abstract}
The effect of Rice Husk Ash (RHA) and Graphene $(G)$ on morphological and physico-mechanical properties on recycled aluminium alloy matrix hybrid composites prepared by stir cast technique was investigated. The method for synthesizing aluminium-based matrix composite materials with 0.4 wt.\% graphene nanoparticles and $0.8 \%, 1.2 \%$ and $1.6 \mathrm{wt} \%$ RHA at 150 m particle sizes, such that RHA provided additional carbon and also acted as a carrier to disperse graphene in aluminium (Al) matrix is entirely new. The composite melt was poured into a preheated die cavity steel moulds to produce rectangular and circular bars. The bars were machined to standard samples for morphological, mechanical, and physical property investigations. Microstructural/chemical composition analyses of reinforcements, control sample and composites were carried out using optical and scanning electron microscopes (OM and SEM) with attached energy dispersive X-ray spectroscopy (EDS). Phases were identified using an Xray diffractometer (XRD). The OM and SEM/EDS micrographs showed fairly homogenous distribution of RHA and graphene within matrix of aluminium alloy. The increase in carbon content of $A l / R H A / G$ composites as revealed in the EDS when compared to composites of Al/RHA confirmed the retention of nanocarbon platelets. The XRD revealed transformation of graphene to amorphous carbon and fullerene $\left(C_{60}\right.$ and $\left.C_{70}\right)$. Also, there was no phase reaction leading to formation of harmful aluminium carbide $\left(\mathrm{Al}_{4} \mathrm{C}_{3}\right)$. Rather, formation of metal-metal, carbon-metal and carbon-metal-oxygen atomic bonds were revealed in the XRD, which led to improved ultimate tensile strength, hardness and fatigue properties of the composites with increase from 63.45 to $132.50 \mathrm{MPa}, 75.50$ to $115.60 \mathrm{HV}$ and $0.72 \times 10^{6}$ to $2.46 \times 10^{6} \mathrm{cycles}$ respectively. However, a noticeable decrease was observed in impact energy and density as percent weight fraction of RHA increases from 13.60 to $8.14 \mathrm{~J}$ and $2.85 \times 10^{3}$ to $2.62 \times 10^{3}$ $\mathrm{Kg} / \mathrm{m}^{3}$ respectively. Therefore, the developed composites are suitable in the production of automotive pistons, push rods and airframe where operations in very high thermal, tribological and mechanical conditions are required.
\end{abstract}

Keywords: Rice husk ash, Graphene, Recycled aluminium cans, Stir cast, Composites

*Corresponding author email: kunleyk2003@yahoo.com 


\section{Introduction}

Metal matrix composites are used in production of automotive, industrial, manufacturing and aviation industries. Composite materials with matrices of aluminium alloys are the most commonly in use as a result of several beneficial physical and mechanical properties (Prasad and Asthana, 2004; Stojanovic and Babic, 2014; Miracle, 2005; Stojanovic et al. 2013). However, challenges such as low temperature capability, unfavourable thermal expansion coefficient and insufficient mechanical, and tribological characteristics limit the use of monolithic aluminium alloy in most areas of applications especially in production of automobile and aerospace components.

Improvement of physical, mechanical and tribological properties of composites by reinforcing either in single or hybrid forms with boron carbide $\left(\mathrm{B}_{4} \mathrm{C}\right)$, Rice Husk Ash (RHA), carbon nanotubes (CNT) coconut shell ash (CSA), bamboo ash (BA), tungsten carbide (WC), bagasse, silicon carbide $(\mathrm{SiC})$, alumina $\left(\mathrm{Al}_{2} \mathrm{O}_{3}\right)$, graphite $(\mathrm{Gr})$, and silica $\left(\mathrm{SiO}_{2}\right)$ have so far been applied (Vencl, 2012; Stojanovic and Barbic, 2014; Vencl et al., 2014; Stojanovic and Ivanovic, 2015). Most engine parts of automotive and aerospace are normally subjected to operations in very unsuitable tribological, thermal (up to $3000{ }^{\circ} \mathrm{C}$ ) and at a cyclic mechanical conditions with frequency above $100 \mathrm{~Hz}$ which might lead to fatigue and other forms of damages, making them to become inevitable for consideration for better use (Stojanovic and Ivanovic, 2015).

Ovid'Ko (2014) submitted that it is possible to develop metallic materials with high strength, hardness and Young Modulus through the new discoveries and very effective approach by embedding graphene platelets, and few layer sheets in metallic matrices.

Due to numerous uncommon properties, graphene is now being employed worldwide for various industrial and manufacturing applications. Graphene has been described as the strongest, stiffest, greatest elastic crystal and thermally conductive material ever measured to the man's knowledge (Prashantha and Xavior, 2014; Lee et al., 2008). Graphene has shown proven records in terms of strengths, electrical and heat conduction due to these unique properties. Prashantha and Xavior (2014) reported that graphene was experimentally demonstrated in the laboratory in 2004. Since then, research of graphene has grown exponentially and presently involves the modification and improvement of the graphene films on various substrates, using graphene as reinforcement and identifying various useful areas of graphene applications.

Production of Al composite from graphene despite its influence on mechanical and thermal properties is confronted with many challenges especially where improved tensile property of the metal matrix composite is required. Stir casting method of production results in poor dispersion of nanoparticles; this is because carbon nanoparticles like graphene have dispersion problems in the melt of $\mathrm{Al}$ matrix as a result of initial entanglement or agglomeration through weak van der Walls bonds. Also, formation of second phase particles which include $\mathrm{Al}_{4} \mathrm{C}_{3}$ is another major problem in the use of stir casting techniques.

Therefore, making the use of solid-state techniques become more popular and its being considered as better processing routes. This is because mechanical dispersion of 
such nanoparticles into metals by severe plastic deformation of the $\mathrm{Al}$ matrix is enhanced (Lim et al., 2009; Esawi and Borady, 2008; Choi et al., 2008; Esawi et al., 2009; Choi et al., 2012; Perez et al., 2009; Choi et al., 2014). It has also been reported that processes that could result in severe mechanical energy will lead to a high level of damage in carbon nanoparticles. Choi et al. (2012) and Perez et al. (2009) stressed that such effects could cause undesirable chemical interfacial reactions between the damaged carbon nanoparticles and the metal matrix during hightemperature consolidation processes.

On the other hand, if powder metallurgy method is used in the production of aluminium/graphene composites, graphene may stick to the surface of the aluminum particles during milling and during consolidation, and subsequent heating and extrusion, graphene may react with the aluminum on the grain boundaries to form aluminum carbide, which may lead to reduction in mechanical properties as a result of points of brittle weakness (Bartolucci et al., 2011). Choi et al. (2014) emphasis that graphene would not be of importance value for automotive, aerospace and other industrial/structural composite applications without solving the critical problem in dispersion and by extension, formation of harmful second phase $\mathrm{Al}_{4} \mathrm{C}_{3}$.

The study is aimed at filling the matrix of Aluminium alloy (Al) with rice husk ash (RHA) and graphene (G) to develop a hybrid Aluminium metal matrix composite with improved physical and mechanical properties suitable in the production of aerospace and automotive components and parts. This method for synthesizing aluminium-based matrix composite materials with low concentration graphene (nanocarbon platelets) and macro particles
RHA, such that RHA provides additional carbon and also acts as a carrier to disperse graphene in aluminium (Al) matrix is entirely new.

\section{Materials and Methods}

Disposed aluminium cans (Plate 1a) of about $18 \mathrm{~kg}$ was melted in the $30 \mathrm{~kg}$ ceramic-lined crucible pot placed in a diesel-fired crucible furnace (Plate 1b) situated at Foundry Workshop, Lagos State Polytechnic, Ikorodu. The charge was heated to about $850{ }^{\circ} \mathrm{C}$ in a continuous process to produce the unreinforced aluminium billets (Durowoju et al., 2017). The rice husk was placed inside a crucible pot and then burnt at $700{ }^{\circ} \mathrm{C}$ for two hours inside the muffle furnace. The ash was further burnt at 1100 ${ }^{\circ} \mathrm{C}$ for another two hours, sieved and graded into particle size of $150 \mu \mathrm{m}$ (Plate 1c). Graphene powder (Nanocarbon platelets) of thickness: $<5 \mu \mathrm{m}$ and lateral Size: $0.5-5 \mu \mathrm{m}$ was purchased from Graphitene Ltd., Manchester, United Kingdom (Plate 1d) (Durowoju et al., 2017).

Aluminium/Rice husk Ash (A1/RHA) composites was first produced by reinforcing the unfilled Al billets with 0.8 , 1.2 and $1.6 \mathrm{wt} . \%$ RHA at $150 \mu \mathrm{m}$ particle size. Each aluminium alloy billet was first preheated at $450{ }^{\circ} \mathrm{C}$ before melting at $750{ }^{\circ} \mathrm{C}$ and rice husk ash of the required percent weight fraction was measured and preheated to about $100{ }^{\circ} \mathrm{C}$ before incorporating into the melt which was then degassed to control the porosity. To reduce the surface tension (improve wettability) between the rice husk ash and aluminium melt, 1 wt. $\%$ of magnesium was simultaneously added into the molten melt. Saravanan and Kumar (2013), stressed that particles of rice husk ash will be rejected without addition of magnesium. 


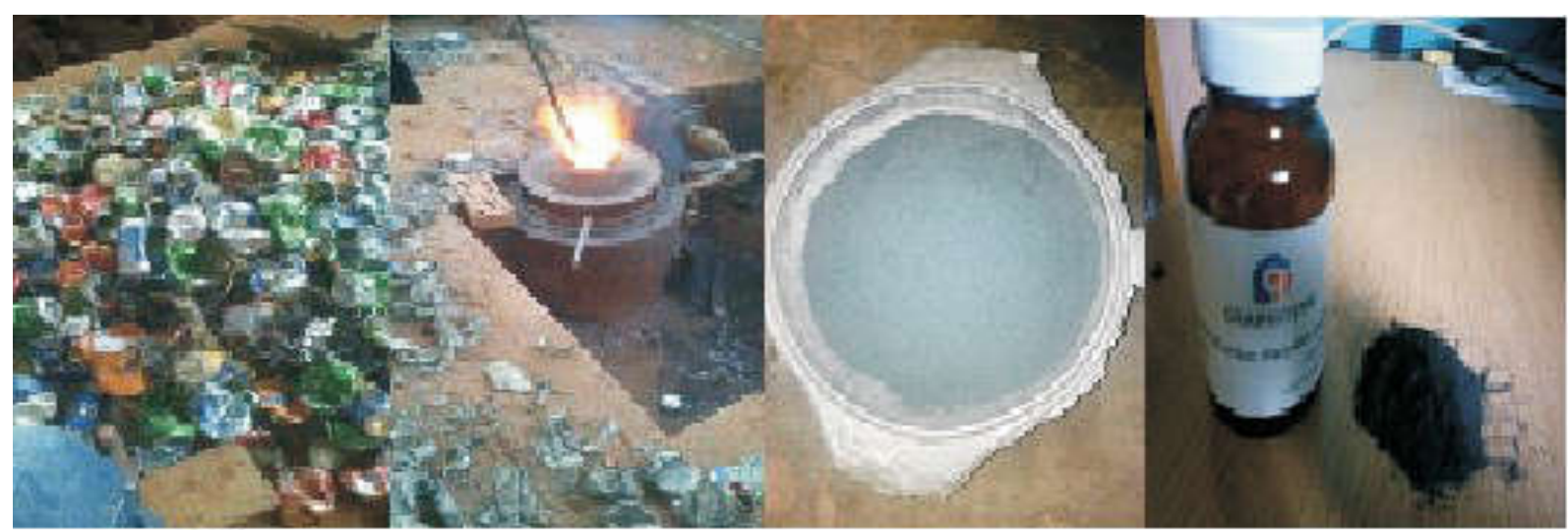

(a)

(b)

(c)

(d)

Plate 1: (a) Disposed Al Cans (b) Crucible furnace (c) $150 \mu \mathrm{m}$ RHA (d) Graphene Nanoplatelets

The molten metal was stirred by the improvised mobile stirrer at a speed of 140 rpm for $2 \mathrm{~min}$. This stirring speed and stirring time were carefully selected, taking into consideration, the capacity and dimensions of the crucible pot, the weight of molten aluminium (about $1 \mathrm{~kg}$ ) and pouring temperature. This was used to produce all composites (plate 2a). Half of the mixture was poured into the fabricated circular and rectangular die cavity metal moulds (plate 2b) which has been preheated to about 200 ${ }^{\circ} \mathrm{C}$ before pouring to produce rectangular and circular bars (plates 2c) of $\mathrm{Al} / \mathrm{RHA}$ composites while the remaining half was immediately used for the production of aluminium/Rice Husk Ash/Graphene (Al/RHA/G) composites after 0.4 wt. \% graphene was simultaneously mixed with $0.8,1.2$ and 1.6 wt.\% RHA to produce rectangular and circular bars.

At the end, seven samples (i.e. one control sample, three composites of $\mathrm{Al} / \mathrm{RHA}$ and three $\mathrm{Al} / \mathrm{RHA} / \mathrm{G}$ composites) were produced for characterization and mechanical analysis. Chemical compositions of the control aluminium alloy sample were determined using Hilger Analytical Direct Optical Light Emission Polyvac Spectrometer, Model E980C. Rice husk ash composition was determined with Shimadzu XRF-1800. Optical and Scanning electron microscopes were used to provide basic information about the microstructure of the samples. The prepared samples were mechanically ground progressively using Struers TegraPol 25 Grinding and Polishing Machine.

The microstructure and the chemical compositions of the phases present in the test samples were studied using a 3000inverted metallurgical optical microscope and JOEL JSM 5900LV Scanning Electron Microscope equipped with an Oxford $\mathrm{INC}^{\mathrm{TM}}$ energy dispersive spectroscopy system. The polished samples were firmly held on the sample holder using a doublesided carbon tape before putting the mini side the sample chamber. The SEM was operated at an accelerating voltage of 5 to 20 $\mathrm{kV}$. The XRD analyses of the control sample and composites was carried out using a PAN analytical X'Pert PRO with $\mathrm{Cu}-\mathrm{K} \alpha$ radiation monochromating multilayered mirrors. The XRD was operated at $45 \mathrm{kV}$ voltage and $40 \mathrm{~mA}$ current. The $2 \theta$ angles between $1^{\circ}$ and 
$90^{\circ}$ were scanned following Bragg's law. A Rietveld refinement software, TOPA ${ }^{\mathrm{TM}}$, was used for quantitative analysis.

The tensile test was prepared according to ASTM E8 (2008) and tensile test conducted at room temperature using Instron Extensometer, (model: Instron 3369), system ID: 3369S3457. Tensile test specimen is shown in Plate 3a. The tensile properties of the samples were obtained from the engineering stress-strain curves generated to determine the ultimate tensile strength (UTS). The hardness test was carried on Vickers hardness testing machine (LECO AT700 Micro Hardness Tester). All samples were prepared with a fine-grained emery polishing papers. The specimen was mounted on a Vickers hardness testing machine using phenolic powder, grinded and then polished to produce a hardness specimen with a smooth surface finish. Then at any clear view of the grains the diamond indenter was then indented under an applied load of $490.3 \mathrm{Nm}(50.03 \mathrm{~kg})$ with a dwelling time of 10 secs at three different points and the depth of penetration of the indenter on the specimen was noted and read directly from the calibrated gauge of the machine.

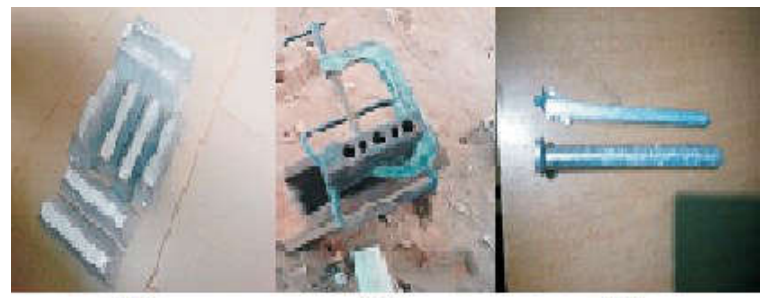

(a)

(b)

(c)

Plate 2: (a) composite billets (b) die metal cavity mould (c) rectangular and circular bars

Plate $3 b$ shows the micro hardness specimens. The impact energies absorbed to fracture of the control sample and composites were measured with Avery Denison Universal Impact Testing Machine according to ASTM A370 standard specimen size for Charpy impact testing shown in plate $3 \mathrm{c}$. Fatigue test was carried out on SM 1090 Rotating Fatigue Machine (Tec Equipment Ltd, 2014). Specimens were prepared with ASTM E466 standard dimensions for different sizes and weight fractions (plate 3d). Count to fracture for each specimen were taken and recorded at constant load and rate.

\section{Results and Discussion}

Elemental composition of the unreinforced aluminium alloy billet (matrix) is shown in Table 1, while Table 2 shows the chemical compound of rice husk ash. Plate 4.1 shows the optical micrograph and scanning electron micrographs/EDS of the control sample while Plates $4.2 \mathrm{a}-\mathrm{c}$ to $4.4 \mathrm{a}-\mathrm{c}$ show the optical and scanning electron micrographs with attached EDS of the composites of Al/RHA. Composites of $\mathrm{Al} / \mathrm{RHA} / \mathrm{G}$ optical and scanning electron micrographs are shown in plates $4.2 \mathrm{~d}-\mathrm{f}$ to 4.4d-f. The XRD diffractograms of the unreinforced Al alloy and RHA are shown in figures $1 \mathrm{a}$ and $\mathrm{b}$. while that of composites of $\mathrm{Al} / \mathrm{RHA}$ and $\mathrm{Al} / \mathrm{RHA} / \mathrm{G}$ are shown in figures $2 \mathrm{a}-\mathrm{d}$. Figures $3 \mathrm{a}-\mathrm{e}$ show the effect of RHA and combination of RHA and graphene on the density, micro hardness, ultimate tensile strength, impact energy and fatigue of the various composites of Al/RHA and $\mathrm{A} 1 / \mathrm{RGHA} / \mathrm{G}$ produced. The effects of reinforcements (RHA and graphene) on microstructure and physico-mechanical properties are discussed.

\section{Chemical Composition}

Major elements in the recycled $\mathrm{Al}$ alloy (control sample) apart from $\mathrm{Al}$ as revealed by the composition analysis are $\mathrm{Cu}, \mathrm{Mn}, \mathrm{Zn}$ and Ti. These elements influenced the phase reactions formed when reinforcements were 
added at various percent weight fraction. XRay fluorescence (XRF) analyser also

revealed chemical compound of RHA.

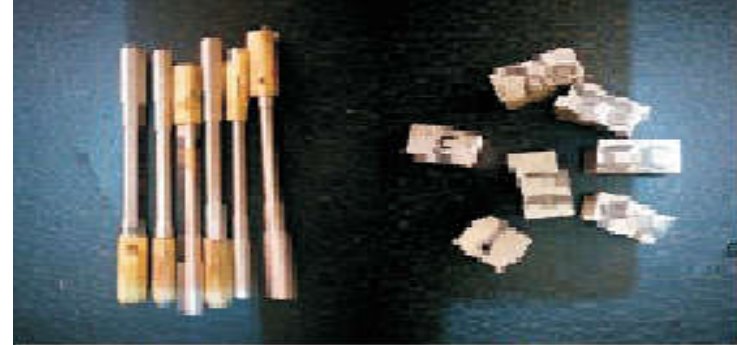

(a) (b)

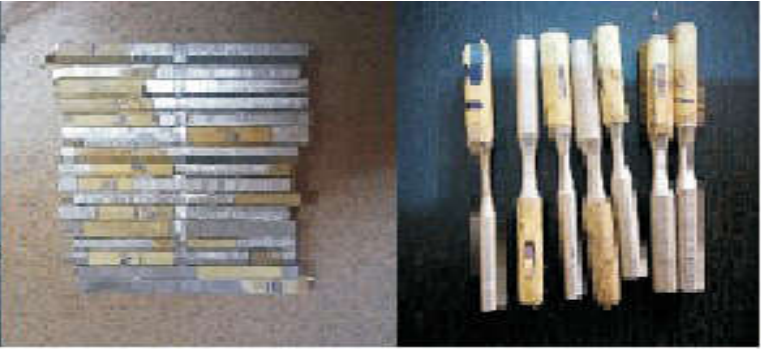

(c) (d)

Plate 3: (a) Tensile specimen (b) Hardness specimen (c) Impact specimen (d) Fatigue specimen

Table 1: The elemental composition of the unreinforced cast aluminium alloy ingot

\begin{tabular}{llllllllll}
\hline $\mathrm{Al}$ & $\mathrm{Si}$ & $\mathrm{Fe}$ & $\mathrm{Cu}$ & $\mathrm{Mn}$ & $\mathrm{Mg}$ & $\mathrm{Zn}$ & $\mathrm{P}$ & $\mathrm{Ni}$ & $\mathrm{Ti}$ \\
\hline 94.0218 & 0.825 & 0.332 & 1.065 & 0.770 & 0.0046 & 2.014 & 0.021 & 0.053 & 0.912 \\
$\mathrm{~S}$ & $\mathrm{Cr}$ & $\mathrm{Sn}$ & $\mathrm{Mo}$ & & & & & & \\
\hline 0.016 & 0.005 & 0.0023 & 0.006 & & & & & & \\
\hline
\end{tabular}

Table 2: Percentage chemical compound composition of rice husk ash burnt at $700{ }^{\circ} \mathrm{C}$

\begin{tabular}{cccccccccc}
\hline $\mathrm{SiO}_{2}$ & $\mathrm{Al}_{2} \mathrm{O}_{3}$ & $\mathrm{Fe}_{2} \mathrm{O}_{3}$ & $\mathrm{CaO}$ & $\mathrm{MgO}$ & $\mathrm{SO}_{2}$ & $\mathrm{~K}_{2} \mathrm{O}$ & $\mathrm{Na}_{2} \mathrm{O}$ & Others & LOI \\
\hline 97.095 & 1.135 & 0.316 & 0.073 & 0.825 & 0.146 & 0.181 & 0.092 & Balance & 0.965 \\
\hline
\end{tabular}

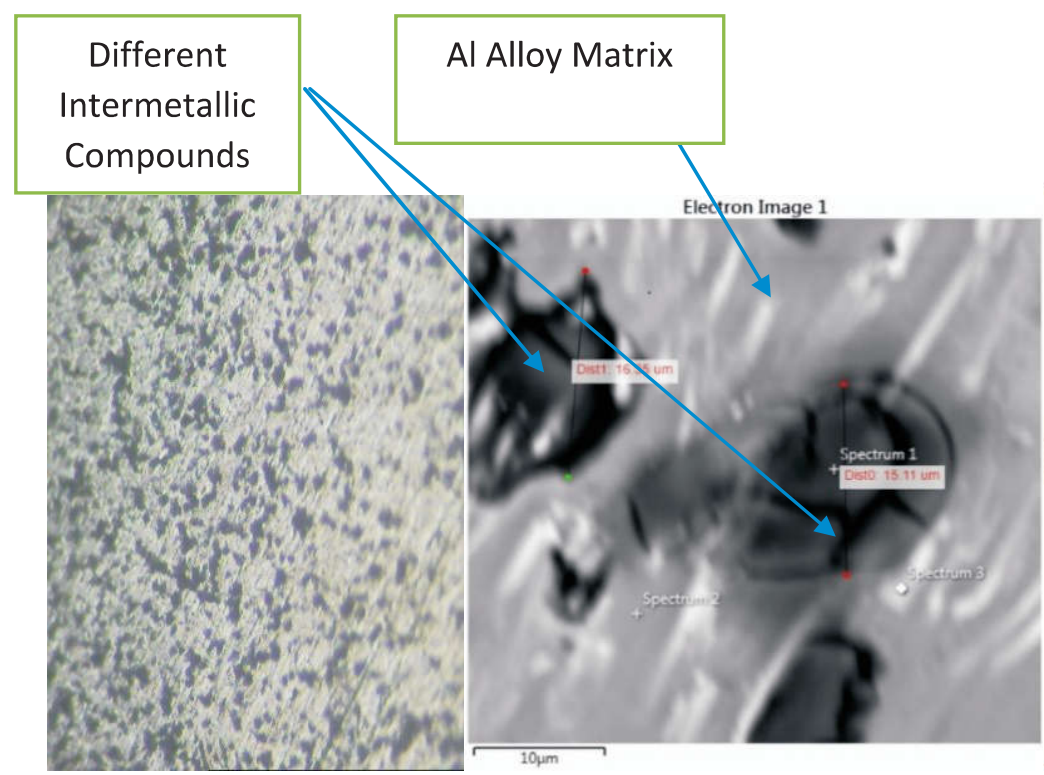

(a) (b)

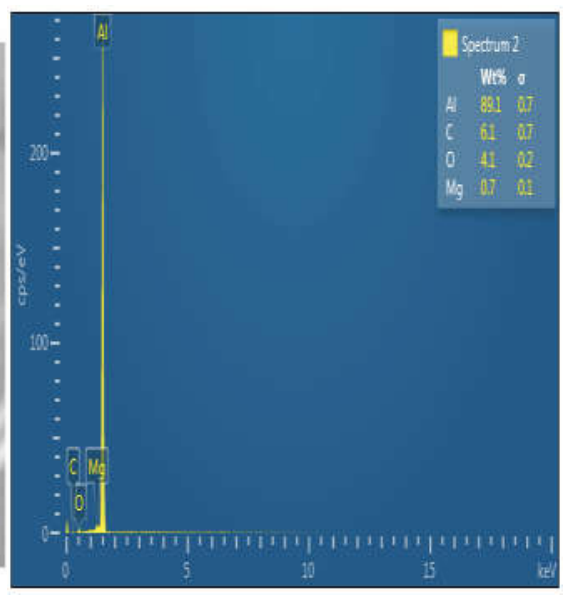

(c)

Plate 4.1: Micrographs of control sample (recycled Al cans) (a) optical micrograph 100X (b) SEM 4000X (c) EDS 


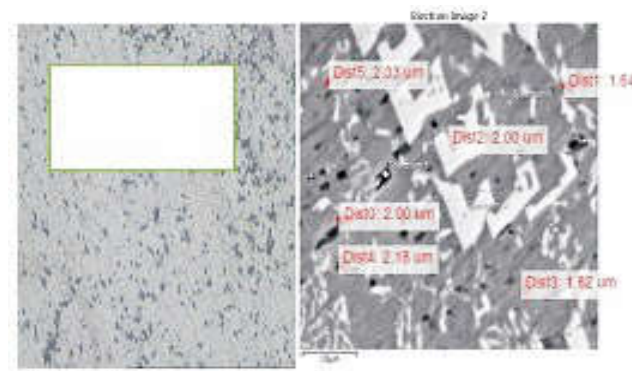

(a)

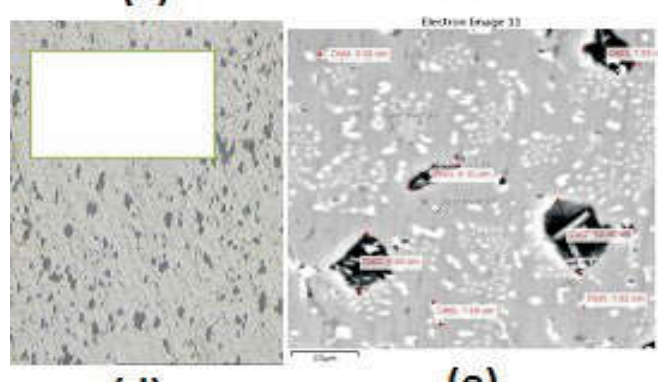

(d) (b)

(e)

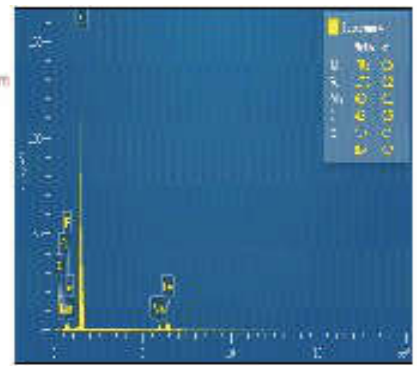

(c)

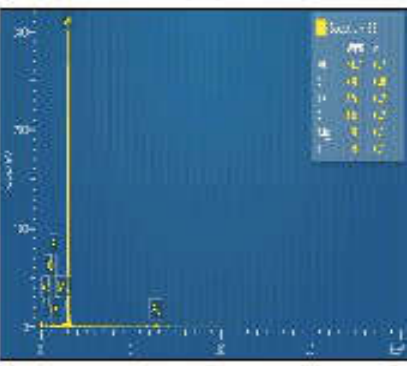

(f)

Plate 4.2: Micrographs of composites at $150 \mu \mathrm{m}$ particle size, $0.8 \mathrm{wt} . \%$ of RHA (a) OM at 100X of A1/RHA (b) SEM at 4000X of A1/RHA (c) EDS of A1/RHA (d) OM of A1/RHA/G (e) SEM of $\mathrm{Al} / \mathrm{RHA} / \mathrm{G}$ (f) EDS of Al/RHA/G

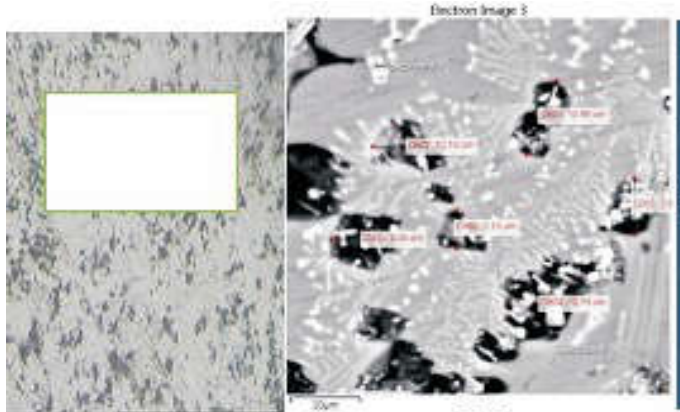

(a)

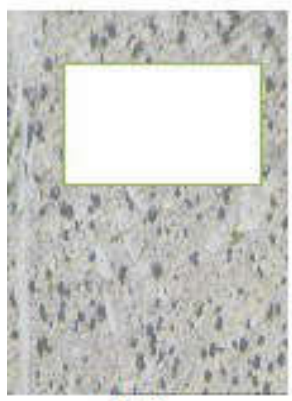

(d) (b)

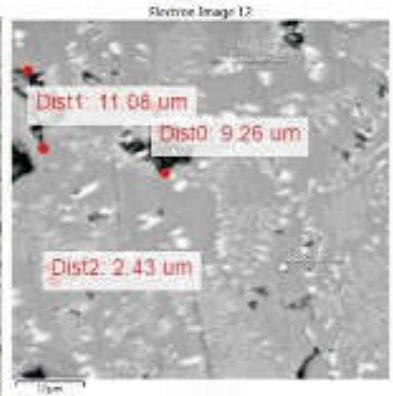

(e)

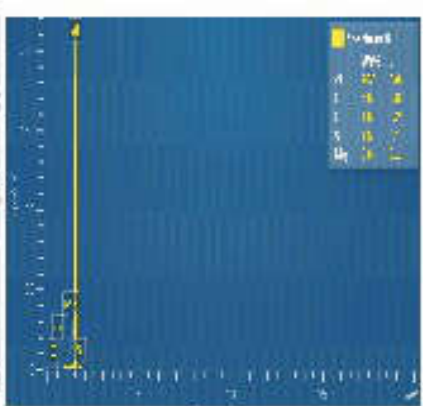

(c)

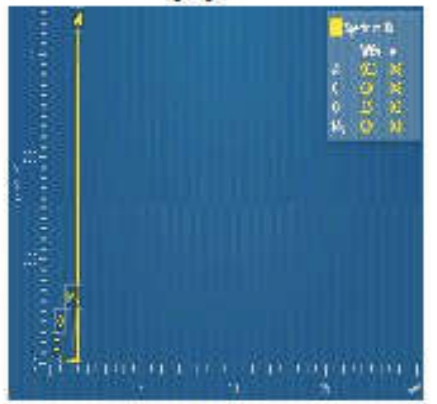

(f)

Plates 4.3: Micrographs of composites at $150 \mu \mathrm{m}$ particle size, $1.2 \mathrm{wt} \%$ of RHA (a) OM at 100X of Al/RHA (b) SEM at 4000X of Al/RHA (c) EDS of Al/RHA (d) OM of Al/RHA/G (e) SEM of $\mathrm{Al} / \mathrm{RHA} / \mathrm{G}$ (f) EDS of Al/RHA/G 


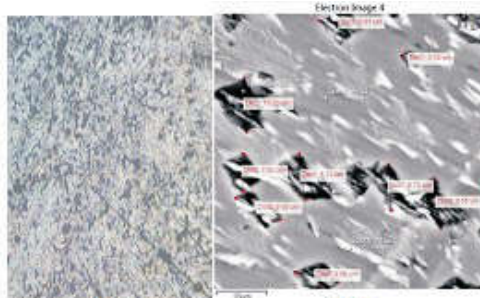

(a)

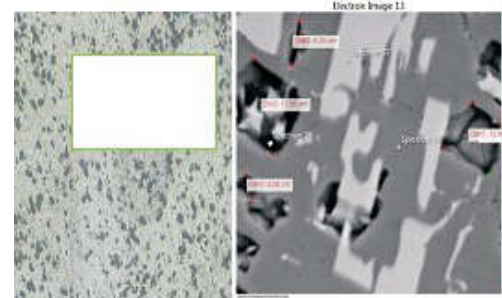

(d)

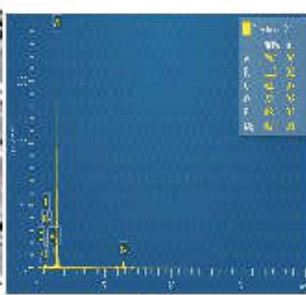

(c)

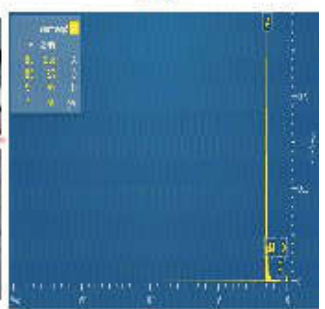

(f)
Plates 4.4: Micrographs of composites at $150 \mu \mathrm{m}$ particle size, 1.6 wt. $\%$ of RHA (a) OM at $100 \mathrm{X}$ of Al/RHA (b) SEM at $4000 \mathrm{X}$ of Al/RHA (c) EDS of Al/RHA (d) OM of Al/RHA/G (e) SEM of Al/RHA/G (f) EDS of Al/RHA/G
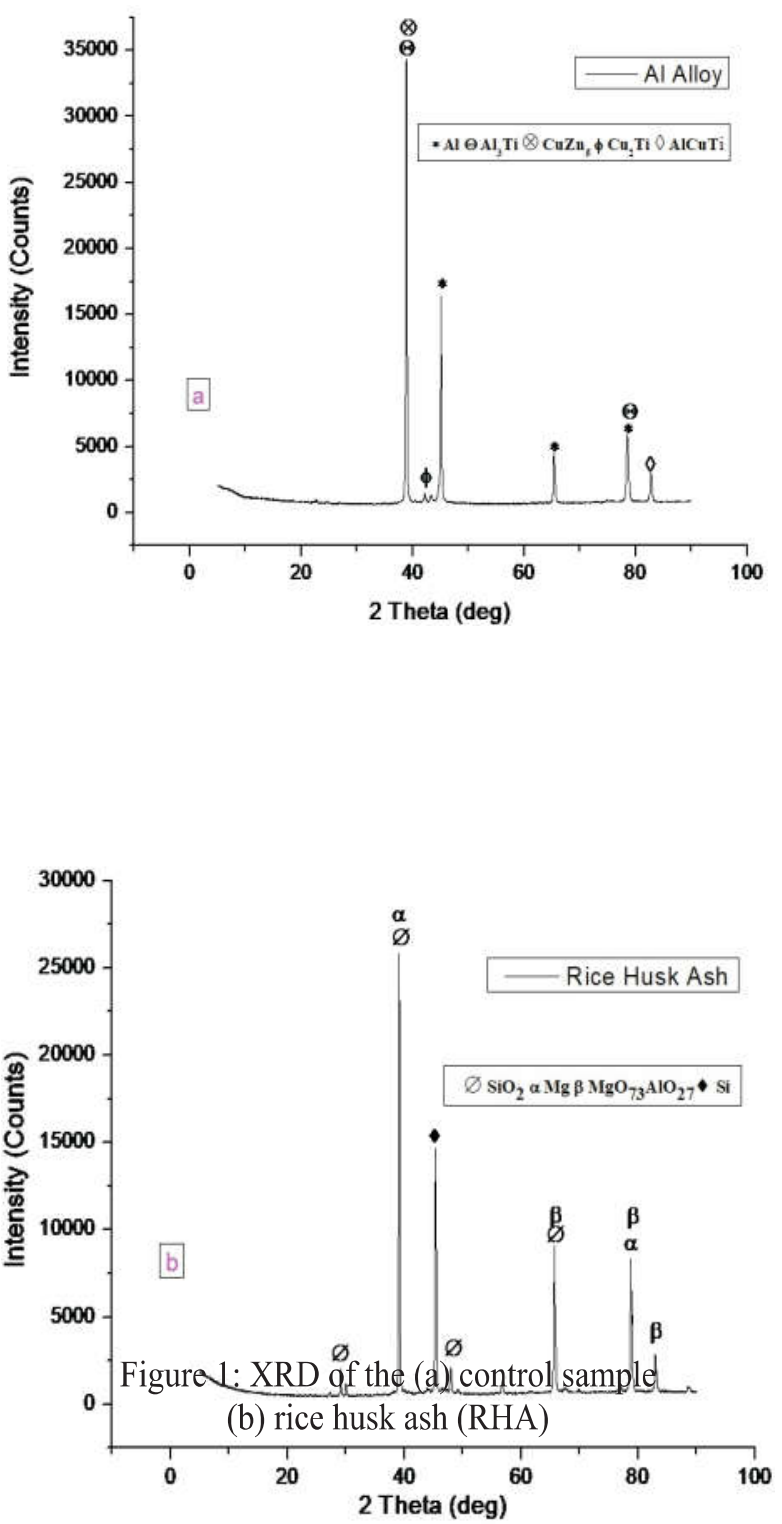


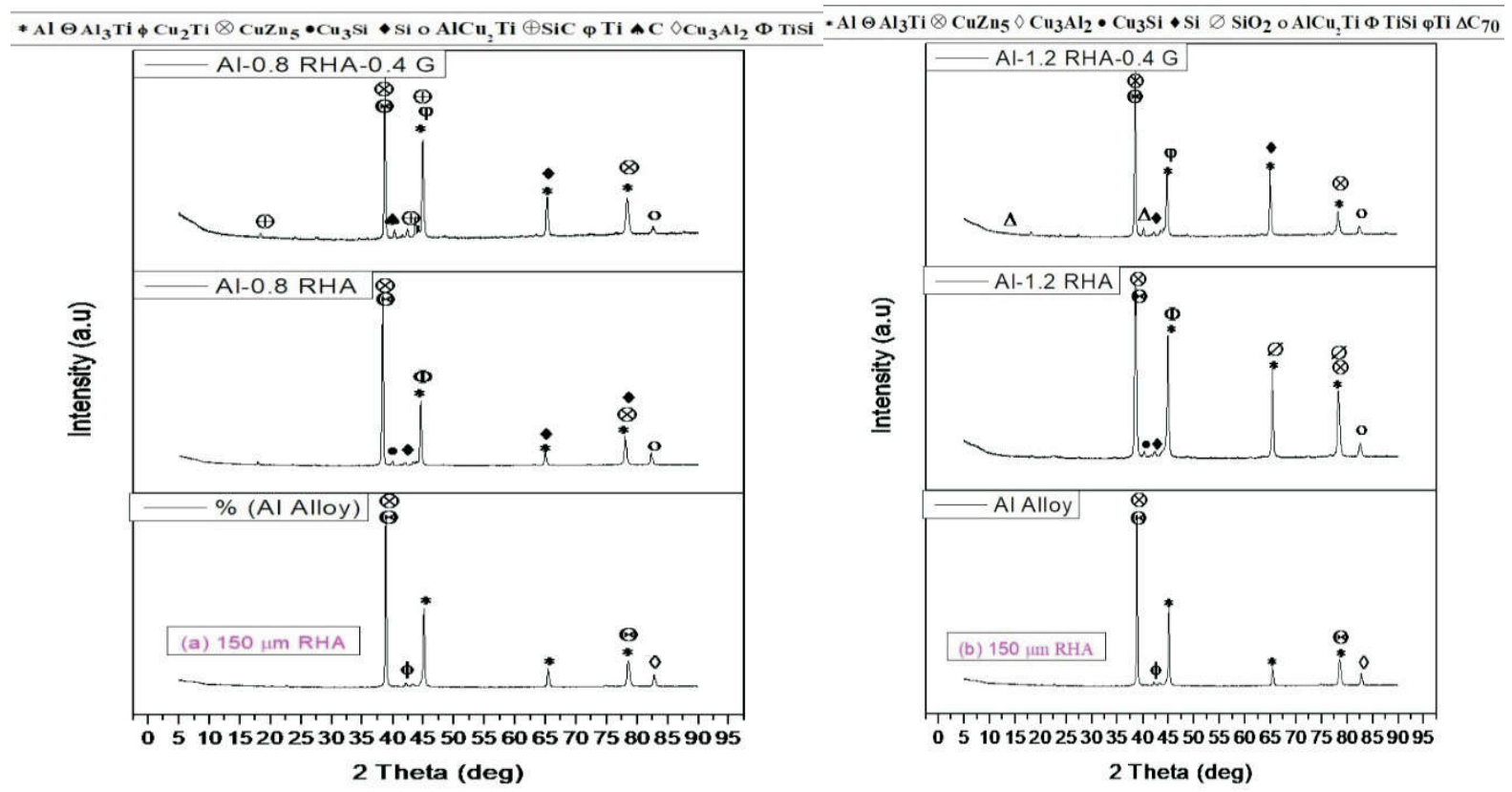

(a)

(b)

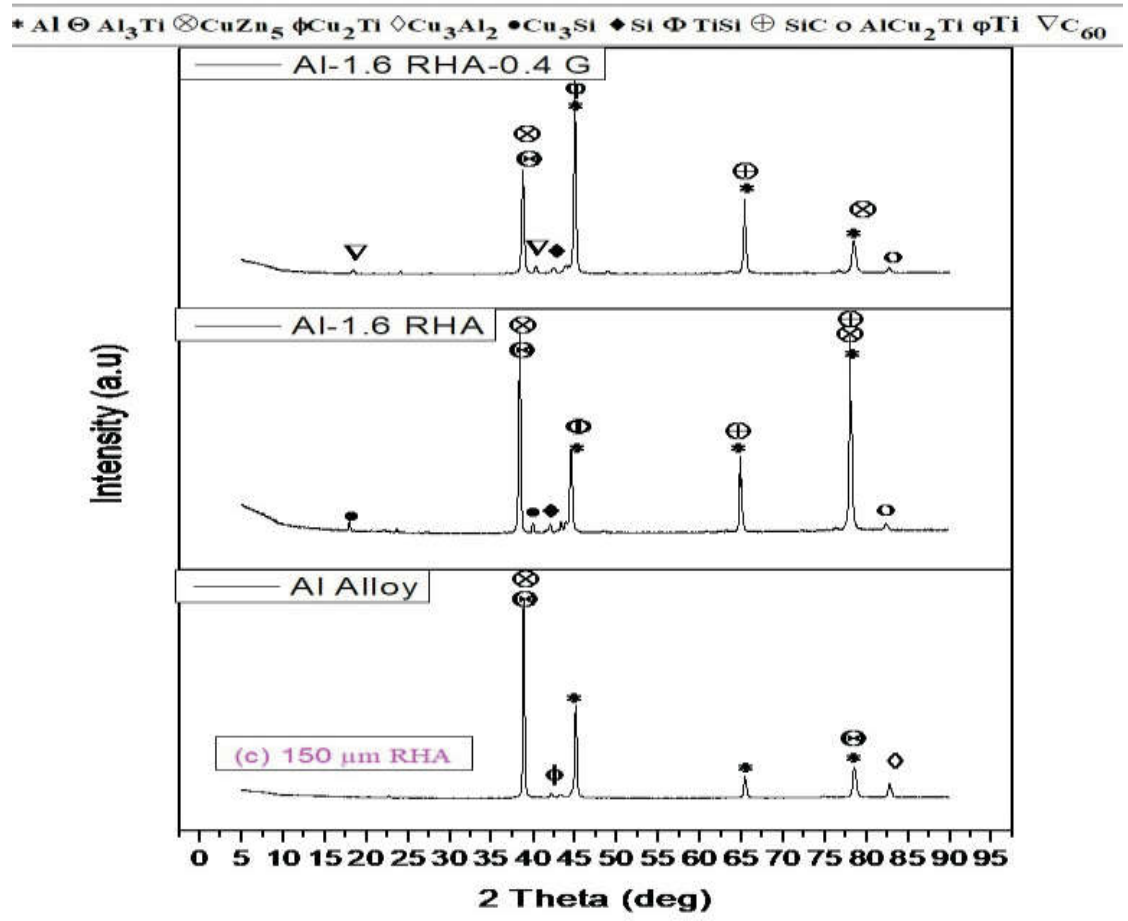

(c)

Figure 2: Combined XRD of control sample, Al/RHA and Al/RHA/G for $150 \mu \mathrm{m}$ size at (a) 0.8 wt.\% RHA (b) 1.2 wt.\% RHA (c) 1.6 wt.\% RHA 
The results in Table 2 showed that the rice husk was properly carbonized as the carbon was not oxidized like other elements.

\section{OM and SEM/EDS Spectrographs}

The OM and SEM/EDS in Plates 4.1a-f to 4.4a-f showed reasonably homogenous distribution of RHA and graphene reinforcements in the matrix of aluminium alloy. This can also be confirmed from the EDS obtained at different locations in each composite. Therefore, the casting grain structure is isotropic and fairly homogenous. The EDS analysis indicated the presence of Al with maximum peak in all castings. Other peaks around $\mathrm{Al}$ peak, which are minor indicate the presence of trace elements having low count score. This observation confirmed the elemental composition of the control sample and the composites.

The consistence presence of carbon (C) in all Al/RHA composites are attributable to the retention of carbonated rice husk added to aluminium alloy as reinforcement. It showed clearly from EDS that these elements increase as the percent weight fraction of the reinforcement's increases. The increase in carbon content as revealed in the EDS of $\mathrm{Al} / \mathrm{RHA} / \mathrm{G}$ composites when compared to composites of Al/RHA also confirmed the retention of graphene nanoparticles.

\section{XRD Diffractometers}

XRD graphs of the unreinforced Al shown in Figure 1a revealed that the major diffraction peaks appeared at diffracting

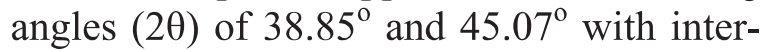
planar distance of $2.32 \AA$ and $2.01 \AA$ and relative $\mathrm{X}$-Ray diffracting intensities of 27756.48 and 11197.12. Intermetallic bond that formed around $\mathrm{Al}$ are $\mathrm{CuZn}_{5}, \mathrm{Al}_{3} \mathrm{Ti}$ and $\mathrm{Cu}_{3} \mathrm{Al}_{2}$. These occurred due to chemical reaction between $\mathrm{Al}$ and other major elements in the recycled $\mathrm{Al}$ cans during melting and solidification. X-ray diffractometric profiles of RHA particulate is shown in Figure 1b. Major diffraction peaks appeared at diffracting angles $(2 \theta)$ of $29.60^{\circ}, 39.65^{\circ}, 43.40^{\circ}$ and $48.73^{\circ}$ with interplanar distance of $3.02 \AA, 2.27 \AA, 2.09 \AA$ and $1.91 \AA$ and relative X-Ray diffracting intensities of $1256.10,355.38,341.56$ and 515.81. The corresponding phases at these peaks are $\mathrm{SiO}_{2}, \mathrm{Si}, \mathrm{SiO}_{2}$ and $\mathrm{SiO}_{2}$. In all composites, reactions between $\mathrm{Al}, \mathrm{Ti}, \mathrm{Si}$, $\mathrm{Cu}, \mathrm{Fe}, \mathrm{SiO}_{2}$ and $\mathrm{Mn}$ to form compounds are clearly seen. These elements formed various intermetallic bonds within the composites and improved the mechanical properties of the composites in different stages of processing.

However, major and common diffraction peaks occurred at diffracting angles $(2 \theta)$ of about $39^{\circ}, 42^{\circ}, 43^{\circ} 45^{\circ}, 65^{\circ}, 78^{\circ}$ and $82^{\circ}$ with inter-planar distance of about $2.05 \AA$, $2.15 \AA, 2.09 \AA 2.03 \AA, 1.43 \AA, 1.22 \AA$ and $1.17 \AA$ respectively forming compounds due to phase reactions between RHA and graphene with varying relative X-Ray diffracting intensities which depend on types of composites (i.e. Al/RHA or Al/RHA/0.4G), particle size and \% weight fraction. At 0.8 wt. $\%$ RHA, it can be established that formation of $\mathrm{Si}$, Si-metal bond was predominated for Al/RHA composites (Figure 2a).

Upon addition of graphene to obtain hybrid Al/RHA/G composites (Figure 2d), amorphous carbon was noticed, such that reactions leading to formation of $\mathrm{C}, \mathrm{C}-\mathrm{SiC}$, metal- $\mathrm{C}$ and $\mathrm{TiC}$ bonds predominated. This carbon is of very small flakes, less than fullerene (between $\mathrm{C}_{60}-\mathrm{C}_{100}$ ) atom. Phase reaction leading to inter atomic bond of this types is an indication that composites of $\mathrm{Al} / \mathrm{RHA} / \mathrm{G}$ will possess mechanical 
properties better than that of $\mathrm{Al} / \mathrm{RHA}$ composites. Al/RHA composites at $1.2 \mathrm{wt} . \%$ RHA (Figure $2 b$ ) revealed oxidation of $\mathrm{Si}$ to $\mathrm{SiO}_{2}$ forming bond with $\mathrm{Al}, \mathrm{Ti}, \mathrm{Zn}$, and $\mathrm{Cu}$. When graphene was added to RHA to produce Al/RHA/G (Figure 2e), transformation of graphene molecules to smaller molecule like $\mathrm{C}_{70}$ fullerene was noticed, forming metal- $/ \mathrm{C}_{70} / \mathrm{C}$, metal-SiC, and metal-Si bonds. This is an index to good mechanical performance of $\mathrm{Al} / \mathrm{RHA} / \mathrm{G}$ composites when compared to the control sample (unreinforced Al alloy) and Al/RHA composites. Formation of $\mathrm{SiC}$ from RHA was revealed at $1.6 \mathrm{wt}$ \% RHA (figure 2c) with metal-metal, metal-SiC and metaloxide inter atomic bond for Al/RHA composites.

However, reaction of graphene with RHA also revealed transformation of graphene flakes to smaller molecules called fullerene of $\mathrm{C}_{60} . \mathrm{Al} / \mathrm{RHA} / \mathrm{G}$ composites (figure $2 \mathrm{f}$ ) are characterized with metal-oxide, $\mathrm{C}_{60}-\mathrm{SiO}_{2}$, metal-metal and metal-SiC atomic bonds. Phase reactions of this type go a long way to confirm that $\mathrm{Al} / \mathrm{RHA} / \mathrm{G}$ composites possess good mechanical properties when compared to monolithic Al alloy and Al/RHA composites.

Thus, it can be established that as $\%$ weight fraction of RHA increases from $0.8 \%$ to 1.6 $\%$, relative $\mathrm{X}$-ray diffracting intensities at the inter-planar distance increases with more minor diffraction peak being revealed due to increase in rate of phase reaction. The mechanism behind the transformation of graphene to fullerene could have been powered by the reactions between rice husk ash in form of amorphous carbon and graphene due to high temperature (about 900 ${ }^{\circ} \mathrm{C}$ ) of mixing and stirring of the mixture in the crucible pot, coupled with high liquidsolid transformation pressure in the die cavity steel mould during casting. There is also possibility of the graphene flakes used to have vacancy at the middle. Such graphene flakes according to Adriano and Elena, (2013) are energetically unstable, and the probability of return motion back to the middle is not likely.

Therefore, graphene structure breaks to very small clusters of carbon atoms such as $\mathrm{C}_{2}$, which afterward joined together to form fullerene enclosures through a series of intermediates. This fullerene cages formed directly from graphene is also believed to have a relatively narrow range of diameters with average about $1 \mathrm{~nm}$, corresponding to 60-100 carbon atoms. Direct visualization of formation of fullerene from graphene sheet is possible using aberration-corrected transmission electron microscopy (Chuvilin et al., 2010).

\section{Densities}

From Figure 3a, it is revealed that the density of the produced composites decreases with increase in the percent weight fraction of RHA and graphene addition. The value decreased from $2.85 \mathrm{x}$ $10^{3} \mathrm{~kg} / \mathrm{m}^{3}$ for the control sample to $2.62 \mathrm{x}$ $10^{3} \mathrm{~kg} / \mathrm{m}^{3}$ at $1.6 \%$ RHA and $0.4 \% \mathrm{G}$ $(\mathrm{Al} / \mathrm{RHA} / \mathrm{G})$ which is equivalent to $8.07 \%$ reduction in density. The decrease in densities is believed to have resulted from the hard and low density RHA and graphene addition which replaces the soft and denser Al matrix in the composites, subsequently giving the composites total reduction in densities. This result is in line with previous work where RHA was varied from $2 \%$ to 8 $\%$ in Al alloy matrix (Usman et al, 2014a; Prasad and Krishna, 2011).

\section{Hardness Properties}

The effect of weight fraction of RHA and graphene particles on micro hardness of the $\mathrm{Al} / \mathrm{RHA}$ and $\mathrm{Al} / \mathrm{RHA} / \mathrm{G}$ composites is depicted in Figure $3 \mathrm{~b}$. It is very obvious 
from the results that the reinforcements of RHA and graphene particles have significant effects on the micro hardness of the composites. Observations clearly revealed that the increase in weight fractions of the reinforcements results in increase hardness.
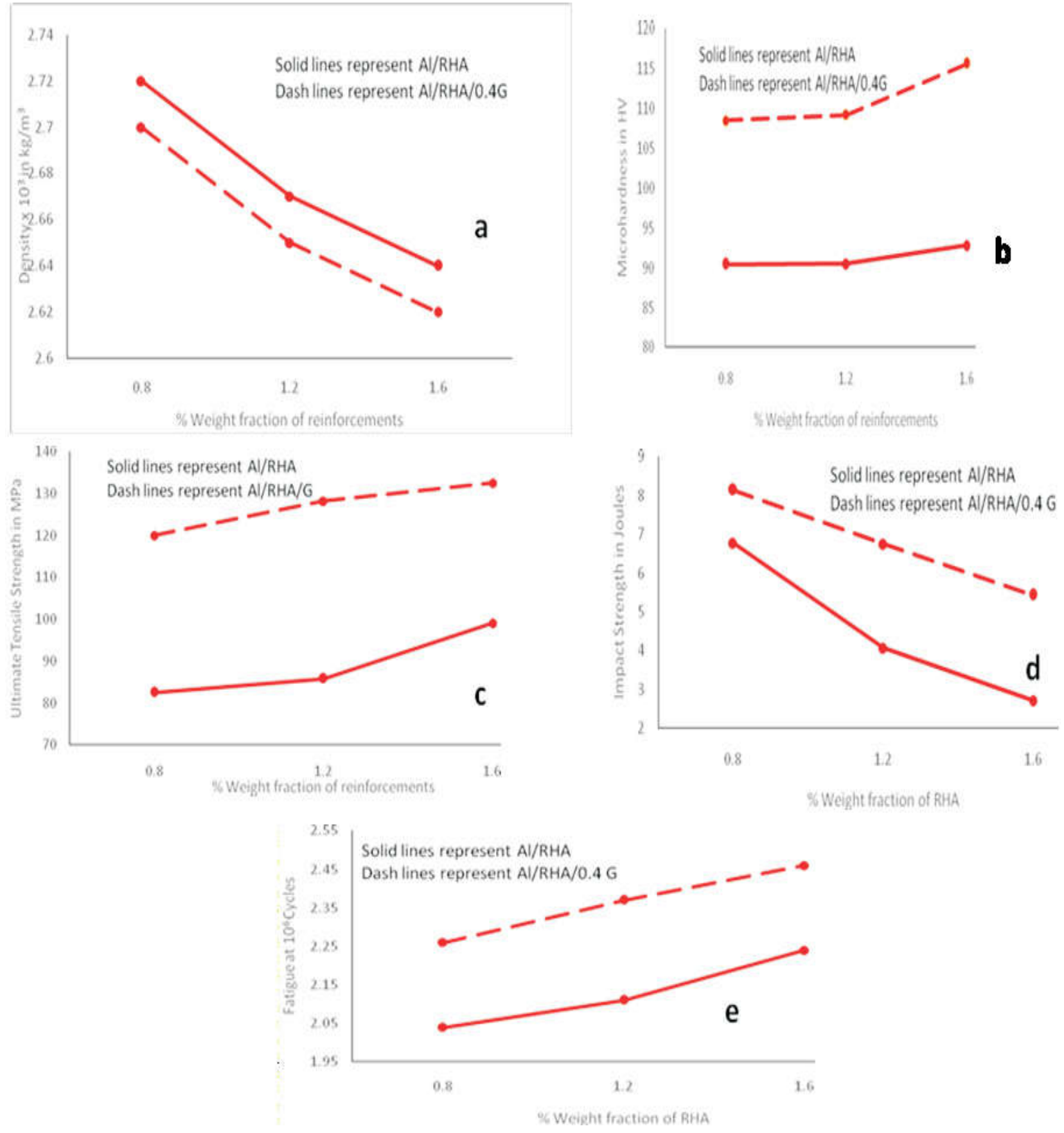

Figure 3: Graphs of Al/RHA and Al/RHA/G composites for (a) densities (b) microhardness (c) ultimate tensile strength (d) impact energy (e) fatigue 
Saravanan et al. (2013) attributed this to increases in surface area of the matrix which then reduces the particle sizes. Also, the presence of reinforcing particles with such hard surface area tends to offer more resistance to plastic deformation and then, increase in hardness is resulted. When compared to the hardness values of control sample $(75.5 \mathrm{HV})$, all the composites showed increase in hardness. With respect to $150 \mu \mathrm{m}$ particles size of RHA, about $22.9 \%$ increase was observed when the reinforcement addition was increased to $1.6 \%$ wt. fraction of RHA particulates in the composites. Hardness was enhanced by $53.1 \%$ increase when graphene nanoparticles were added to the same RHA particles.

\section{Ultimate Tensile Strength (UTS)}

The relation between tensile strength of the control sample of $\mathrm{Al}$ alloy and fabricated composites of $\mathrm{Al} / \mathrm{RHA}$ and $\mathrm{Al} / \mathrm{RHA} / \mathrm{G}$ with the different weight fractions is shown in figure 3c. It can be observed for both Al/RHA composites that the ultimate tensile strength increases as the weight percentage of rice husk ash increases. The ultimate tensile strength of composites increased from $63.45 \mathrm{MPa}$ for the control sample to $92.80 \mathrm{MPa}$ for $150 \mu \mathrm{m}$ particle size at 1.6 wt.\% RHA. The improvement in the UTS of both $\mathrm{Al} / \mathrm{RHA}$ and $\mathrm{Al} / \mathrm{RHA} / \mathrm{G}$ composites is linked to the increase diffusion rate of reinforcements which could lead to deep penetration into the matrix of $\mathrm{Al}$ to form a good interfacial binding between the $\mathrm{Al}$ matrix and RHA/G. The improvement is also due to increase in packing density of each of the reinforcement which were evenly dispersed throughout the Al matrix.

Also, distribution of reinforcements within the Al matrix could result in chemical reactions between RHA and graphene leading to the formation of fullerene $\left(\mathrm{C}_{60}\right.$ and $\left.\mathrm{C}_{70}\right)$ and various intermetallic compounds such as $\mathrm{CuZn}_{5}, \mathrm{Al}_{3} \mathrm{Ti}, \mathrm{CuSi}$, $\mathrm{SiC}, \mathrm{AlCu}_{2} \mathrm{Ti}$, etc. occupying interstices between $\mathrm{Al}$ lattice sites. The presence of these new phases gave rise to an elastic straining effect as revealed from a change in the inter-planar spacing from $1.43 \AA$ of a phase in the unreinforced $\mathrm{Al}$ to $2.02 \AA$ of one of the phases in the Al/RHA composites. This straining effect together with barriers to dislocation movement could have contributed to improvement in the UTS. According to Bello et al. (2015), the impediment to movement of dislocation became more pronounced as the packing density of the reinforcements increased and this also resulted in piling up of dislocation at the grain boundaries and new compounds' sites such that any further dislocation movement would be induced by additional application of force. Hence, the strengthening of the composites.

\section{Impact Energy}

From figure $3 \mathrm{~d}$, it can be inferred that impact energy of all composites (Al/RHA and $\mathrm{Al} / \mathrm{RHA} / \mathrm{G}$ ) decreased from the control sample of $13.60 \mathrm{~J}$. The reduction in impact energy may be linked to excessive hardness of the newly formed phases which introduced brittleness to the $\mathrm{Al}$ matrix. Also, the unreinforced $\mathrm{Al}$ alloy with porosity freecoarse fibrous grain microstructure tends to inhibit crack growth, leading to higher absorption of impact energy than that of reinforced composites. Hence, it is obvious that the addition of reinforcements to the $\mathrm{Al}$ matrix improved the strength and refinement of coarse grain structure but reduced the impact energy. The impact energy decreased with weight fraction, with smallest value of $2.71 \mathrm{~J}$ at $1.6 \%$. Addition of graphene to the RHA revealed increase in the impact strength for all $\mathrm{Al} / \mathrm{RHA} / \mathrm{G}$ 
composites at about $1.25 \%$. These results are in conformance with Usman et al. (2014b) using of rice husk ash (RHA) and bagasse ash (BA) as reinforcements with Al-7 \% Si as matrix. However, information on the influence of graphene on impact strength of aluminium alloy is rare.

\section{Fatigue}

It can be seen in figure $3 \mathrm{e}$ that the number of cycles to fracture of composites increase with the rice husk ash addition from $0.72 \mathrm{x}$ $10^{6}$ cycles for the control sample to $2.24 \mathrm{x}$ $10^{6}$ cycles for $150 \mu \mathrm{m}$ particle sizes respectively at 1.6 wt.\% RHA. It follows that with increase in reinforcement addition up to $1.6 \%$ for RHA, the fatigue strength of the composites increased. Chawla and Chawla, (2004) argued that the improved fatigue behaviour of the particulate reinforced compared to unreinforced alloy is attributable to the higher stiffness of reinforcing materials in the composites. By extension, such improvement is as a result of the lower stress concentration in the composite where the matrix is surrounded by high stiffness reinforcement particles than in the unreinforced alloy. Also, since high stiffness reinforcement particles in the composite carry more of the load, it means that the Al matrix in the composites will be subjected to lower stress than in the unreinforced alloy (Usman et al., 2014a). With addition of graphene of higher stiffness, the fatigue strength of the Al/RHA.G composites has further improved by about $1.2 \%$.

\section{Conclusion}

From the present investigation, it can be concluded that composites of $\mathrm{Al} / \mathrm{RHA}$ and Al/RHA/G were successfully produced from recycled waste aluminium cans, rice husk ash and graphene. Utilization of these waste materials in production of $\mathrm{Al}$ composites will help in converting waste to wealth.

The morphology of the composites revealed reasonably homogenous distribution of RHA and graphene in the matrix of aluminium alloy. Formation of metal-metal, carbonmetal and carbon-metal-oxygen atomic bonds was revealed in the XRD. Upon addition of graphene nanoparticles with the RHA, phase reaction leading to transformation of graphene into fullerene occurred. The XRD of all composites did not reveal formation of a harmful second phase particle like $\mathrm{Al}_{4} \mathrm{C}_{3}$.

Investigation of the physico-mechanical characteristics showed that the percentage weight fraction of RHA and addition of low concentration graphene have significant effect on density, ultimate tensile strength, hardness, impact and fatigue strengths of the composites. The density and impact energies of composites decrease with increase in percent weight fraction. Ultimate tensile strength, hardness and fatigue strength of the composites increased with increase RHA addition up to $1.6 \%$. Such composite is suitable for automotive piston, push rod and airframe with density, hardness, tensile and fatigue strength ranging from 2.43-2.74 $\mathrm{g} / \mathrm{cm}^{3}, 104-143 \mathrm{HV}, 120-235 \mathrm{MPa}$ and 2.05 $\times 10^{6}-2.88 \times 10^{6}$ respectively.

\section{References}

Adriano, S. and Elena B. 2013. Stability and dynamics of vacancy in graphene flakers: edge effects. Chemical Physics Letters 558: 80-87.

Bartolucci, S.F., Paras, J., Rafiee, M.A., Rafiee, J., Lee, S., Kapoora, D. and Koratkar, N. 2011. Graphene-Aluminum nanocomposites. Materials Science and Engineering A528: 7933-7937. 
Bello, S.A., Agunsoye, J.O. and Hassan, S.B. 2015. Synthesis of coconut shell nanoparticles via a top down approach: Assessment of milling duration on the particle sizes and morphologies of coconut shell nanoparticles. Materials Letters 159: 514-519.

Chawla, N. and Chawla, K.K. 2004. Metal Matrix Composites, Kluwer Academy Publisher, Boston.

Choi, H.J., Kwon, G., Lee, G. and Bae, D. 2008. Reinforcement with carbon nanotubes in aluminum matrix composites. Scripta Materialia 59(3): 360-363.

Choi, H.J., Seo, I., Bae, D. and Choi, K. 2014. Mechanical properties of aluminumbased nanocomposite reinforced with fullerenes. 9th International Conference on Fracture and Strength of Solids June 9-13, 2013, Jeju, Korea.

Choi, H.J., Shin, J.H. and Bae, D.H. 2012. The effect of milling conditions on microstructures and mechanical properties of Al/MWCNT composites. Composites Part A: Applied Science and Manufacturing 43(7): 1061-1072.

Chuvilin, A., Kaiser, U, Bichoutskaia, E., Besley, N.A. and Khlobystov, A.N. 2010. Direct transformation of graphene to fullerene. Nature Chemistry 2: 450-453.

Durowoju, M.O., Agunsoye, J.O., Mudashiru, L.O, Yekinni, A.A., Bello, S.K. and Rabiu, T.O. Optimization of Strir casting process parameters to improve the hardness property of $\mathrm{Al} / \mathrm{RHA}$ matrix composites. European Journal of Engineering Research and Science 2(11): 512

Esawi, A.M.K. and Borady, M.A. 2008. Carbon Nanotube-Reinforced Aluminium Strips. Composites Science and Technology 68(2): 486-492.
Esawi, A.M.K., Morsi, K., Sayed, A., Gawad, A.A. and Borah, P. 2009. Fabrication and properties of dispersed carbon nanotube-aluminum composites. Materials Science and Engineering 508(12): 167-173.

Lee, C., Wei X.D., Kysar, J.W. and Hone, J. 2008. Measurement of the elastic properties and intrinsic strength of monolayer graphene. Science 321(5887): 385-388.

Lim, D.K., Shibayanagi, T. and Gerlich, A.P. 2009. Synthesis of multi-walled CNT reinforced aluminium alloy composite via friction Stir processing. Materials Science and Engineering 507(1-2): 194-199.

Miracle, D.B. 2005. Metal matrix composites - From science to technological significance. Composites Science and Technology 65: 2526-2540.

Ovid'Ko. 2014. Metal-Grapene Nanocomposites with enhanced mechanical properties. a review. Advanced Material Science 38: 190-200.

Pérez-Bustamante, R., Gómez-Esparza, C.D., Estrada-Guel, I., Miki-Yoshida, M., Licea-Jiménez, L. and Pérez-García S.A. 2009. Microstructural and mechanical characterization of Al-MWCNT composites produced by mechanical milling. Materials Science and Engineering 502(1-2): 159-163.

Prasad, S.V. and Asthana, R. 2004. Aluminum metal-matrix composites for automotive applications: Tribological considerations. Tribology Letters 17: 445453.

Prashantha, K.H.G. and Xavior, M.A. 2014. Graphene reinforced metal matrix composite: a review, $12^{\text {th }}$ Global Congress on Manufacturing and Management Science, Procedia Engineering 97(321): 1033-1040.

Saravanan, S.D. and Kumar, M.S. 2013. Effect of mechanical properties of rice husk 
ash reinforced aluminium alloy (AlSi10Mg) metal matrix composites. Procedia Engineering 64: 1505-1513.

Stojanović, B., Babić, M., Mitrović, S., Vencl, A., Miloradović, N. and Pantić, M. 2013. Tribological characteristics of aluminum hybrid composites reinforced with silicon carbide and graphite. A review, Journal of the Balkan Tribological Association 19: 83-96.

Stojanovic, B. and Babic, M. 2014. Optimization of $\mathrm{A} 356 / 10 \mathrm{SiC} / 3 \mathrm{Gr}$ hybrid composite wear using Taguchi method. 8th International Conference on Tribology, Sinaia, Romania. pp. 708-715.

Stojanovic, B. and Ivanovic, L. 2015. Application of aluminium hybrid composites in automotive industry. Technical Gazetti 22(1): 247-251.

Usman, A.M., Raji, A., Hassan, M.A. and Waziri, N.H. 2014a. A comparative study on the properties of Al-7\% Si-rice husk ash and Al-7\% Si-bagasse ash composites produced by Stir casting. The International Journal of Engineering and Science (IJES) 3(8): 23191813.

Usman, A.M., Raji A., Hassan, M.A. and Waziri, N.H. 2014b. Aluminium alloy - rice husk ash composites production and analysis. Leonardo Electronic Journal of Practices and Technologies 25: 84-98.

Vencl, A. 2012. Tribology of the Al-Si alloy based MMCs and their application in automotive industry, Magagnin L. (edition), Engineered Metal Matrix Composites: Forming Methods, Material Properties and Industrial Applications, Nova Science Publishers, Inc., New York (SAD). pp. 127166.

Vencl, A., Bobic, I. and Stojanovic, B. 2014. Tribological properties of A356 Al-Si alloy composites under dry sliding conditions. Industrial Lubrication and Tribology 66: 6674. 